\title{
"CHRIST TRANSFORMING CULTURE"? NAGEDINK OOR DIE AARD VAN DIE GEREFORMEERDE GELOOF
}

\author{
D. Smit ${ }^{1}$ \\ ABSTRACT \\ "CHRIST TRANSFORMING CULTURE"? \\ REFLECTIONS ON THE NATURE OF \\ REFORMED FAITH
}

\begin{abstract}
The essay pays tribute to the honoree by reflecting on the nature of the Reformed faith and tradition, in which he was called to play a leading role during challenging times. It takes its departure in H. Richard Niebuhr's well-known claim that the Reformed faith represents a form of "Christ transforming culture" Christianity, implying both that the Reformed faith positively affirms reality and life and that Reformed faith continuously strives for transformation and renewal of reality and life. The essay demonstrates how this twofold emphasis, of affirmation and critical renewal at the same time, is rooted in the heart of the Reformed vision itself, which is described as "a way of being the Christian community in the world, before God". Four aspects of this description are consecutively highlighted, namely "the Christian community" (the first section), "before God" (the second section), "a way of being" (the third section) and "in the world" (the fourth section). In a concluding section the essay argues that four popular forms of criticism of the Reformed faith, widespread in South Africa today, are therefore directed at caricatures and betrayals of the Reformed tradition.
\end{abstract}

\section{NOGEENS: WAT BETEKEN GEREFORMEERD?}

Die jubilaris was bevoorreg om oor etlike jare 'n leidende rol te speel binne die gereformeerde kerke-familie in Suid-Afrika. Dit was veelbewoë tye van snelle sosiale en politieke veranderinge, maar ook van ekonomiese, wetenskaplike, lewensbeskoulike en kulturele veranderinge. Met reg was meermale sprake van prosesse van radikale transformasie - en die kerk, insluitende die gereformeerde kerke in Suid-Afrika, waar onder ook die Neder-

1 Prof. D. Smit, Departement Sistematiese Teologie, Universiteit van Stellenbosch. 
duitse gereformeerde Kerk waarin hy 'n besondere leiersposisie ingeneem het, was meesal in die hart van hierdie radikale prosesse betrokke.

Die aard van hierdie kerklike betrokkenheid in die Suider-Afrikaanse samelewing en sy ingrypende transformasies was en bly kompleks. Intense debat word steeds - byvoorbeeld — gevoer oor die presiese aard van die wisselwerking tussen kerk en kultuur gedurende die uiteenlopende fases van hierdie omstrede tye. Het die kerk die samelewing (soms) beïnvloed? Of was dit altyd andersom, en die kerklike veranderinge net die weerspieëling en die neerslag van beslissings wat elders geval en tendense wat elders ontwikkel het? (Sien Smit 2002c, maar ook die talle ander bydraes in dieselfde uitgawe.)

Hoe dit ook sy, dit bly onomstrede dat daar karakteristieke trekke verbonde is aan die eie aard van die gereformeerde geloof wat onvermydelik meebring dat gereformeerde Christene en kerke nie alleen ten diepste betrokke voel by wat in die werklikheid aan die gebeur is nie, maar wat ook meebring dat hulle nie vreemd staan teenoor vernuwing en selfs radikale transformasie nie. Anders as talle ander geloofsgemeenskappe en tradisies kan die gereformeerde geloof dit as't ware, gegee sy eie diepste oortuigings en patos, nie vermy om by die samelewing en die werklikheid betrokke te bly nie, en daarby trouens doelbewus in diens te staan van vernuwing en verandering nie.

H. Richard Niebuhr sou dié aard van die gereformeerde tradisie probeer vasvang in sy bekende beskrywing daarvan as 'n vorm van "Christ transforming culture"-geloof - enersyds neem dit die werklikheid en die volle lewe baie ernstig en positief op, maar andersyds behou dit voortdurend 'n kritiese afstand van enige histories gegewe gestalte van die werklikheid en die lewe en probeer dit in diens staan van voortdurende verandering en vernuwing (Niebuhr 1951; sien Smit 1990 vir die komplekse funksie van dié beskrywing binne Niebuhr se eie ontwikkeling, en vir talle sinonieme uitdrukkings vir "transformasie" wat hy gebruik het).

Uiteraard maak dié tipies gereformeerde geneigdhede die lewe van ampsdraers en leiersfigure — soos die jubilaris — dikwels nie maklik of eenvoudig nie, maar sekerlik tog opwindend en uitdagend! Miskien kan enkele gedagtes ter herinnering aan dié tipiese aard van die gereformeerde geloof help om meer lig te werp op die vele uitdagings waarvoor die gereformeerde kerke in Suid-Afrika die afgelope dekades gestaan het en waarvoor hulle steeds staan.

Maar: wat beteken "gereformeerd"? Dis geen eenvoudige vraag nie, en dis ook nie 'n onskuldige vraag nie. Dit is nie sonder rede dat daar juis die 
afgelope dekade of meer, wêreldwyd, maar juis ook in Suider-Afrikaanse geledere, so herhaaldelik oor hierdie vraag gepraat, geskryf, nagevors en gedebatteer is nie (sien byvoorbeeld Willis \& Welker 1999 met talle bydraes, asook De Gruchy 1991 se indringende en Burger 2001 se entoesiastiese en tog self-kritiese bespreking, as enkele voorbeelde onder talle uit Suid-Afri$\mathrm{ka}$, asook Smit 1988, 1989, 1992). Die onoorsigtelike oorvloed van materiaal hieroor, en juis die uiteenlopende menings wat daarin weerspieël word, die botsende belange wat duidelik daaragter sigbaar word en die diep emosionele reaksies wat dié gesprekke oproep, maak almal saam duidelik dat daar geen enkele en korrekte antwoord op die vraag is nie. Dit geld trouens van alle identiteitsvrae, soos: wat beteken dit of dat? (sien Smit 1998a en 1998 b vir die narratiewe struktuur van identiteitsvrae en -antwoorde).

Tog is daar meer en minder verhelderende antwoorde moontlik, en ten minste een van die meer informatiewe benaderings mag dalk wees om 'n suggestie van die gesaghebbende Amerikaanse John Leith (1981) te volg en uit te brei, en gereformeerdheid te verstaan as 'n manier om die Christelike geloofsgemeenskap in die wereld te wees, voor die aangesig van God ("a way of being the Christian community in the world, before God"). Met die eerste oogopslag mag dit baie vaag klink, maar byna elkeen van die uitdrukkings binne hierdie omskrywing dui op 'n tipiese kenmerk van die hart van die gereformeerde tradisie.

\section{2. "DIE CHRISTELIKE GELOOFSGEMEENSKAP..."}

'n Sleutelkenmerk van die gereformeerde tradisie was dat hulle nie gereformeerd wou wees nie, maar Christelik, algemeen Christelik, deel van en saam met alle ander Christene. Hoe vanselfsprekend dit ook al mag klink, openbaar dit 'n diepe drif in die gereformeerde lewensgevoel wat hulle telkens deur die geskiedenis weer sou onderskei van selfs ander Protestantse kerke wat andersins na aan hulle gestaan het.

Soos bekend, het dit reeds by Calvyn self begin. Die Institusie was immers 'n inleiding in die Christelike leer, nie in een of ander soort leer binne die Christendom in onderskeiding van ander nie (Calvin 1977). Daar is min twyfel dat die hartstog agter Calvyn se werk ook was dat Christene hulle sou verenig in hierdie leer en vroomheid, en selfs dat die eenheid van die kerk daardeur gedien en bevorder sou word. Calvyn se eie patos vir die eenheid van die kerk, vir wat vandag die ekumeniese drif en spiritualiteit genoem word, is welbekend en goed gedokumenteer (sien Nijenhuis 1959, ook Stauffer 1986). 
Dis ook geen wonder dat van die bekende figure in die gereformeerde tradisie soveel aandag gewy het aan die katolisiteit van die Christelike geloof nie. Uit die Nederlandse tradisie hoef 'n mens maar net aan Bavinck (1888) en later aan Berkhof (1962) herinner te word, en in Suid-Afrika self aan die belangrike werk van Willie Jonker oor die katolisiteit van die kerk (1992), waar onder die volheid en, ja, die eenheid verstaan word - die volheid van die waarheid, die volheid van die werklikheid, die volheid van die kerk van alle eeue, die volheid van die heerskappy van Jesus Christus oor alles en almal.

Dit is gevolglik nie verbasend dat gereformeerdes sovele sleutelrolle sou speel met die opkoms van die ekumeniese beweging in die laat negentiende eeu en dan veral in die twintigste eeu nie. Of dit nou in die drie groot ekumeniese strominge was wat sou saamvloei, te wete Faith and Order, Life and Work en die International Mission Society, later Mission and Evangelism, en of dit in die talle ander ekumeniese insiatiewe was op kampusse, in skole, in Bybelvertaling of in Sondagskool, en of dit in die administrasie, die publikasie-afdeling of die algemene sekretariaat van die amptelike ekumene was - internasionaal, maar ook in talle streke en lande, insluitende Suid-Afrika - val die name van gereformeerde leiersfigure telkens op, en om begryplike rede (sien talryke bydraes oor sulke figure asook oor sodanige strominge en vertakkinge van die Ekumeniese Beweging in Lossky et al. 1991).

Hierdie ekumeniese betrokkenheid en ywer was by talle van hulle gebore in die diep gereformeerde drif vir die één kerk en die één waarheid in Gods één heilsekonomie vir die één werklikheid.

Kortom, gereformeerde Christene is diep bewus daarvan dat hulle sáám met ander gelowiges deel van die één Christelike geloofsgemeenskap uitmak en hulle verlang na sigbare en geleefde eenheid met dié breë, katolieke gemeenskap.

\section{3. “... VOOR DIE AANGESIG VAN GOD”}

Hierdie geloofsgemeenskap leef, volgens gereformeerde oortuiging, voor die aangesig van God, coram Deo. Nou kan die hele Reformasie natuurlik geesteshistories só beskryf word, as 'n breë verskuiwing in vroomheid vanaf 'n lewe meer in verhouding met die institusionele kerk na 'n lewe meer in persoonlike verhouding met God, maar selfs binne Reformatoriese geledere is dié lewe coram Deo op uiteenlopende maniere opgeneem — die piëtistiese, mistieke God van die hart, die belewenis, die innerlike en die gevoel, soos by Schleiermacher; die regverdige God van die gewete en die verterende 
aanklag, van die oordeel en die verwerping soos by Luther; of die lewende God wat spreek deur die volle Woord soos by Calvyn verteenwoordig immers almal invloedryke, dog uiteenlopende maniere om die lewe coram Deo te verstaan en te beoefen (sien byvoorbeeld die gesaghebbende studie van Bakker 1956).

Alles hang dus af van die soort Godsvoorstelling wat aanwesig is, wat bepaal hóé die lewe voor die aangesig van God gesien word. Wie God is, sal bepaal hoe die lewe van die Christelike geloofsgemeenskap voor Gods aangesig sal uitsien.

Reeds by Calvyn speel hierdie onverbreeklike samehang tussen Godskennis en selfkennis 'n sleutelrol. Die eerste bladsye van die Institusie maak dit al glashelder duidelik. Daar is geen ware Godskennis sonder selfkennis nie (sien die diepgaande studie van Butin 1995). Eweneens is daar geen ware selfkennis sonder Godskennis nie. In hierdie noue samehang is die volgorde egter van sleutelbelang. Geloof is vir Calvyn faciem Dei contemplari, nadenke oor die aangesig van God. Dié aangesig is egter aan ons getoon, histories aan ons geopenbaar, in Jesus Christus. Geloof is daarom om híerdie angesig van God voortdurend weer te bedink, te bepeins, om ons blywend daarin te verdiep en daaroor te verwonder, want in híerdie lig sien ons die lig, in dié gesig sien ons ook onsself, wie ons waarlik is en sal wees en kan wees.

Dis om hierdie rede dat Calvyn so 'n voorliefde openbaar het vir beelde en metafore wat met sien, met lig, met die son of met 'n bril te make het. Geloof was vir hom om te leer sien, in die aangesig van God in Christus te leer kyk en te leer sien en te leer begryp, óók onsself en alle dinge.

Dit verklaar ook die sleutelrol van die Heilige Skrifte binne sy opvattinge en in die gereformeerde tradisie. Die Heilige Skrifte is die stem van "die lewende God en van sy Christus" self, blywend, deur die eeue, danksy die lewende en lewendmakende Gees. Christene glo volgens Calvyn se voorstelling nie in die Bybel nie, maar in God, die lewende God wat steeds deur die Bybel spreek. Daarom is die hermeneutiese sleutel vir Calvyn geleë in die verbond, of nog beter: in die lewende Verbondsgod, die God van Abraham, Moses, Dawid en die apostels, ja, maar wat ook steeds sy gemeente deur die eeue begelei en versorg deur sy Woord en Gees (vir sy hermeneutiek, sien byvoorbeeld Opitz 1994, maar ook Ganoczy \& Scheld 1983, Torrance 1988, Schwöbel 1990 en Smit 2002d vir groter besonderhede en literatuur).

Dié lewende Christus handel deur sy Woord met sy gemeente as Middelaar, volgens sy drie-voudige amp, as profeet, priester en koning. Dié amp het Hy egter nie net uitgeoefen tydens sy aardse bediening nie; nee, 
juis nou, as lewende Christus en Middelaar werk hy as priester, profeet en koning, na sy hemelvaart en verhoging, stééds, getrou en betroubaar, vandág (sien ook Wainwright 1997 vir 'n waarderende bydrae uit die ekumene vir dié faset van Calvyn se bydrae).

Presies om dié rede leef die gemeente voor die angesig van hierdie lewende God en sy Christus deur voortdurend weer te luister na hierdie lewende Woord, as die stem van die sprekende Drie-Enige God. Niks kan die lees van en die luister na die Bybel ooit vervang nie. Dit is die pilare van die gereformeerde vroomheid - of dit nou in die erediens of tuis plaasvind (Smit 1988).

Ook nie die kerklike leer kan die voortdurende lees van en luister na dié Woord ooit oorbodig maak nie. Hoe belangrik die leer ook al vir die gereformeerde tradisie is, is dié belang uitsluitlik daarin geleë dat dit die gemeente en gelowiges wil lei ná die Woord en déúr die Woord (vir die jubilaris se eie diepe belangstelling in hierdie samehange van gesaghebbende Skrifte en die lees, uitleg en spreke van die kerk, sien Potgieter 1983, 1985 en 1990). Dit geld al van die Institusie self, soos van Calvyn se talle ander genres en geskrifte. Dit is - bloot! — bedoel as handleiding, as bril om op te sit, om beter te kan lees en beter te kan luister en beter te kan hoor.

Alle gelowiges word daarby opgeroep en opgevoed om self die Woord te kan lees en verstaan. Almal moet volwasse word in die geloof en verantwoordelik in hulle alledaagse leef voor die aangesig van dié lewende, sprekende God. Dit is om hierdie rede dat onderrig en skoling, ja, lering en geleerdheid, vir Calvyn en sy nakomelinge so belangrik sou wees.

Selfs die presbiteriale kerkregeringstelsel wat wyd verbreid sou raak deur die gereformeerde wêreld berus op híérdie oortuigings en veronderstel die beoefening daarvan. Die onderskeid tussen geestelikes en leke verdwyn, leierskap binne die gemeente word radikaal anders verstaan. Dit gaan om die regering van Christus in sy kerk, wat geskied deur die lewende Woord — gepreek, gelees, bespreek, verstaan, toegeëien — en alle ampte staan op 'n baie praktiese wyse in diens van hierdie lewe, hierdie eintlike amp van die gelowiges almal tesame, voor Gods aangesig (vergelyk steeds die gesaghebbende Jonker 1965).

Die karakteristieke gereformeerde klem op waarheid, op kennis, op studie, op teologie, op lering en op prediking hang ten nouste hiermee saam. Alles saam staan in diens van hierdie verlange om die stem van die lewende God en sy Christus deur die Woord te hoor in die hede.

Hierdie kennis - soos hierdie waarheid, hierdie lering en hierdie prediking — bly daarom diep histories van aard, kontekstueel, gerig op die ak- 
tuele situasie met sy vrae, uitdagings en geleenthede. Dis nie moontlik om hierdie kennis of teologie op ' $n$ a-historiese, tydlose manier saam te vat in skolastieke of ortodokse lering, wat daarna ongeag situasie of behoefte as tyd- en kontekslose proposisies genoegsaam sou bly nie. Dit sou 'n verloëning van die diepste gereformeerde oortuigings wees, selfs al geskied dit in die naam en ter wille van gereformeerdheid.

Calvyn se eie werk was deur en deur retories van aard en word slegs reg waardeer indien dit steeds so gelees word. Dit beteken dat dit doelbewus kontekstueel was, gerig op spesifieke hoorders en gehore onder spesifieke historiese omstandighede. Die mees verhelderende onlangse studies oor sy werk is juis dié wat van 'n retoriese leesstrategie gebruik maak (sien byvoorbeeld die baanbrekerswerk by Bouwsma 1988, en in Bouwsma \& Wuellner 1987, maar vir toepassings ook Compier 1999 en 2001, Smit 1996b, en veral die uitstekende Jones 1995).

Calvyn was nie alleen self 'n opgeleide en bekwame retor nie, maar 'n mens kan sê dat vir Calvyn die lewende God eweneens soos 'n goeie retor deur die geskiedenis steeds aktueel bly spreek met sy volk, lewend en volgens hulle behoeftes. Dáárom is die voortgaande, plaaslike prediking van Gods Woord sélf Gods Woord — selfs al is dié identiteit ook hoe verborge en bedreig.

Die kontekstuele - en dus historiese en retoriese aard van die Christelike Gods- en selfkennis - kom baie duidelik na vore in die karakteristieke wyse waarop die gereformeerde geloofsgemeenskap die rol van belydenisskrifte sien. Om begryplike redes is belydenisskrifte 'n tipies Protestantse verskynsel (Jonker 1994). Binne die Protestantisme self is daar egter ook nog duidelik onderskeie maniere om oor belydenisskrifte te dink.

Vir gereformeerdes - in opsigtelike onderskeid van byvoorbeeld Lutherse beskouinge - is belydenisskrifte ten diepste histories van aard. Hulle is nie tydlose en daarom universeel-geldige formulerings van die waarheid in die vorm van presiese proposisies nie, maar veeleer historiese, gesitueerde reaksies op heel konkrete behoeftes, vrae en uitdagings. 'n Staat van belydenis noodsaak na die oordeel van spesifieke gelowiges die daad van belydenis. Dit is 'n poging om die waarheid van die evangelie te bely in daardie oomblik en teenoor daardie uitdagings. Ander tye en plekke kan en sal ander belydenisskrifte hê — vandaar die veelvoud van belydenisskrifte in gereformeerde geledere, reeds vanaf die vroegste jare.

Uiteraard kan die waarheid van die belydenis nie bloot eie mening of belange weerspieël nie, maar moet dit gebore word in die hoor van die evangeliewoord van die lewende God en sy Christus — wat dan ook die 
rede is waarom die belydenis publiek afgelê word en blootgestel word aan die kritiese toetsing deur susters en broers, maar nie met die bedoeling dat hulle dit ook hoef oor te neem as hulle eie belydenisse nie.

Hierdie tipies gereformeerde siening van belydenis, wat 'n direkte uitvloeisel is van die gereformeerde siening van die lewe voor die aangesig van die lewende, sprekende God en sy Christus deur sy Woord en Gees, is in die twintigste eeu meermale deur Karl Barth baie duidelik verwoord, en het neerslag gevind in byvoorbeeld die gebeure rondom Barmen en Belhar (sien Barth 1935, 1957a, 1957b, 1957c, maar veral 1957d en 1990g, asook 1998; sien ook Smit 2000 vir Barth en Smit 1998c vir Barth en Belhar, asook Horn 1987).

\section{4. “'N MANIER VAN ... TE WEES”}

Juis dié gereformeerde siening van die aard van belydenis lei vanself tot 'n verdere aspek van die gereformeerde eieaard. $\mathrm{Na}$ gereformeerde oortuiging roep belydenis naamlik om beliggaming, om konkrete, daadwerklike, selfs institusionele gestaltegewing - en weer eens is dit karakteristiek van die gereformeerde lewensgevoel (Smit 2002f).

Die woorde "'n manier ... om te wees" ("a way of being") in die aanvanklike beskrywing verdien naamlik besondere beklemtoning, ten einde goed te begryp wat op die spel staan.

Weer eens vloei hierdie karakteristiek direk uit die tipies Calvinistiese Godsvoorstelling. Wat die gemeente naamlik hoor in die Woord van die lewende God is, volgens Calvyn en sy geesgenote, die wil van die lewende Verbondsgod. Historici en teoloë het al op indringende wyses aangetoon hoe hierdie tipiese aksent by Calvyn — op Gods wil, en dus op gehoorsaamheid, op heiligmaking, op etiek, op die doen van Gods wil - verklaar moet word vanuit die invloede op sy denke en lewe. Vir talle kritici is dit dan ook een van die sleutelplekke waar Calvyn self en saam met hom die gereformeerde lewensgevoel skeefgeloop het, en in allerlei -ismes verval het, waarvan wettisisme en legalisme van die bekendste klagtes is. Dát hierdie klem op die wil van God in die Woord wat ons hoor egter vir gereformeerdes van groot belang is, kan nie ontken word nie, ongeag hoe 'n mens daaroor oordeel.

Juis dié klem gee dan aanleiding tot die gereformeerde belangstelling in die gestaltegewing aan Gods Woord, aan vormgewing, ook aan vorming, aan sigbaarmaking, aan beoefening, aan beliggaming, aan verwerkliking — hoe'n mens ook al verkies om dit te beskryf, en elkeen van hierdie uitdrukkings roep hulle eie assossiasies, toepassings, episodes en figure binne 
die tradisie op (sien byvoorbeeld Russel Botman se beskrywing van dissipelskap as trans-formasie, in aansluiting by Dietrich Bonhoeffer oor die wyse waarop Christus gestalte of vorm anneem in die werklikheid, Botman 1993).

Dis bekend dat Calvyn op sy sterfbed, terugskouend op sy eie lewe, vertel het hoe hy niks aangetref het toe hy die eerste maal in Geneve aangekom het nie. Daar was net prediking, onthou hy, maar geen reformasie nie! Daarmee word sy ander aksent as byvoorbeeld by Luther glashelder. Vir Luther het hervorming juis prediking beteken; Calvyn wou iets meer sien, te wete gestaltegewing (Gerrish 1999, ook Calvin 1971:41).

Dit is immers ook die oorspronklike betekenis van die term "gereformeerd", wat diegene in hierdie tradisie doelbewus en berekend op hulleself van toepassing gemaak het, in onderskeid van ander Protestante, omdat hulle wou sien dat die hele lewe "her-vorm word volgens God se Woord". In sy gesaghebbende beskrywing van die gereformeerde geloof in onderskeid van ander tradisies en gemeenskappe is dan gevolglik ook die punt wat Jaroslav Pelikan beklemtoon. Hulle het gehunker na 'n lewe "nach Gottes Wort reformiert" (Pelikan 1984).

Ook die woorde wat as die bekendste slagspreuk van die gereformeerde tradisie bekend sou raak, die strewe na 'n ecclesia reformata semper reformanda, 'n gereformeerde kerk wat steeds weer reformeer, verwoord hierdie diepgewortelde oortuiging en verlange (sien verskeie opstelle in Willis \& Welker 1999, insluitende die inleidende hoofstuk).

Hierin skuil 'n diepe patos van die gereformeerde lewensgevoel. Wat gehoor word in die Woord, moet bely word met woord en daad, in dankbare gehoorsaamheid. Wat bely word, moet sigbaar omgesit word in gestalte en vorm. Wat ons het en is, word aan die lewende God gewy — soos Calvyn se eie lyfspreuk aangrypend sou illustreer. So was die Institusie self nie bedoel as blote teologie of kennis nie, maar as inwyding in die Christelike vroomheid of piëteit, as handleiding tot 'n praktiese lewe in ooreenstemming met Gods Woord.

Hierdie voortdurende hervorming was daarby so omvattend moontlik gedink en voorgestel. Dit strek uit oor die persoonlike lewe, ja, maar ook oor die kerklike lewe en ook oor die openbare lewe.

Hoe dit oor die persoonlike lewe uitstrek en vra om voortdurende toewyding en heiliging, blyk byvoorbeeld alreeds uit Calvyn se eie beskrywing van die Christelike lewe, soos ook uit die tipies gereformeerde siening van die derde gebruik van die wet, uit die verstaan van heiliging en regverdiging in hierdie tradisie, of ook uit die karakteristiek Calvinistiese siening 
van die mortificatio en die vivificatio (sien die uitstekende behandeling van die lewensheiliging in Jonker 1981, en die studie van Retief 1984).

Hoe dit uitstrek oor die kerklike lewe, word byvoorbeeld sigbaar uit die belangrike plek en funksie van kerkordes binne die gereformeerde vroomheid. Telkens wanneer gereformeerde kerke hulle geloof nuut bely het onder spesifieke historiese uitdagings, het hulle kerkordes opgestel om sigbare gestalte aan daardie geloof te probeer gee. Belydenis roep om beliggaming. Dikwels is juis hierdie aspek beskryf as die tweede Reformasie, die hervorming van die instelling en die gemeentelike lewe en ordening naas die eerste reformasie van die prediking en die verstaan van die evangelie self (sien Adonis 1988, Niesel 1938, Jacobs 1959, Weerda 1964, ook Smit 2002f, vir meer besonderhede en literatuur).

Dis welbekend hoe dié voortdurende vernuwing ook uitstrek oor die werklikheid self, oor die wêreld, oor die openbare lewe met alles wat dit inhou (sien Durand 1986). Jonker sou tereg hieroor — in navolging van Van Ruler - skryf as die brandende visioen in die gereformeerde hart (Jonker 1982, sien vir Van Ruler self die gesaghebbende Lombard 1996). Miskien is dit uiteindelik dié karakteristiek wat die gereformeerde tradisie op die mees opvallende - en vir baie die mees bevreemdende - manier onderskei het van ander gestaltes van die Christelike geloof.

\section{5. “... IN DIE WÊRELD”}

Met dié karakteristiek is 'n laaste aspek van die gereformeerde lewe aangeraak wat só belangrik is dat dit afsonderlike aandag verg, te wete die oortuiging dat die beliggaming van die Christelike lewe in die wêreld en die werklikheid afspeel.

Weer eens wortel hierdie oortuiging in die gereformeerde Godsvoorstelling. Vir Calvyn — soos vir talle latere gereformeerde denkers — is die God voor Wie se aangesig hulle leef die Drie-Enige God van die geskiedenis en van die ganse werklikheid. Die hele wêreld is die teater van God se heerlikheid, sou Calvyn se bekende uitspraak lui. Die lewende God is die Groot Politikus (Lehmann 1963), ja, selfs die Groot Ekonoom (Meeks 1989 en 1995), wat in sy goddelike heilsekonomie by alles betrokke is en alles seënend, versorgend en verlossend rig.

Om volkome begryplike redes beklemtoon feitlik alle bekende tipologieë van Christelike tradisies wat deur die 20ste eeu geskryf sou word telkens hierdie karakteristiek ten einde die gereformeerdes te kan onderskei en plaas binne die veelvoud van moontlikhede binne die Christelike spektrum — 'n mens hoef maar slegs te dink aan figure soos Max Weber (1975), Ernst 
Troeltsch (1912 en 1992), H Richard Niebuhr self (1951) en Nicholas Wolterstorff (1983).

Uiteraard word hierdie betrokkenheid van die lewende God by die geskiedenis en die wêreld ook binne gereformeerde kringe op uiteenlopende en omstrede wyses voorgestel, en die gepaardgaande dankbare en gehoorsame gestaltegewing aan die wil van dié God gevolglik eweneens. Denkbeelde wissel van die bekende motief van die heerskappy van Christus, die hoogs omstrede gedagtegoed veral uit Nederlandse geledere rondom 'n teokrasie, die ewe omstrede Kuyperiaanse voorstellinge van "elke duimbreedte" volgens 'n allesinsluitende gereformeerde lewens- en wêreldbeskouing, die Christokratiese ideale reeds sedert Bucer, die meermale gewilde visie van die koninkryk van God, tot by die komplekse en histories uiters invloedryke verbonds-, federale en gemenebesvoorstellinge. (Sien Smit 2002a, ook vir die probleme daaraan verbinde om onder moderne, sekulêre, demokratiese en pluralistiese omstandighede steeds dié visie vol te hou.)

Hoe dit ook sy, agter al hierdie uiteenlopende, komplekse en — juis vandag — moeilik volhoubare uitbeeldinge skuil 'n tipies gereformeerde logika. Die lewende God is geïnteresseerd in en betrokke by die vernuwing en verlossing van die werklikheid, en daarom behoort die gemeente en die gelowiges eweneens geïnteresseerd in en betrokke by die geskiedenis en die volle werklikheid te wees. Gereformeerdes is geïnteresseerd in die eeue meer as in die ewigheid (Aalders 1969:101).

Dit mak die roeping van gelowiges so 'n sleutelmotief in die gereformeerde denke. Die roeping van die Drie-Enige God - tereg al beskryf as "the threefold call" — gaan uit in die konkrete hier en nou waar gelowiges hulle bevind (Preece 1998). Dis nie 'n roeping uit die wêreld uit nie, maar in die wêreld in. Om dié roeping daadwerklik te hoor, behoort gelowiges gevolglik die Bybel en die koerant sáám te lees, die verrassende woorde van die Gans Andere te hoor juis te midde van die diepe kompleksiteite en weerbarstighede van die volle lewe self (in Barth se bekende woorde uit sy kommentaar op Romeine 12, in Barth 1922).

Vandaar die diepgewortelde neiging tot kontekstualiteit in gereformeerde kringe. Hulle word graag Skotse Presbiteriane, Engelse Puriteine, Nederduitse Gereformeerdes, Black and Reformed, ja, Hongaars en Switsers en Suider-Afrikaans (Botman 1996). Dis selfs moontlik om die invloed van die verbondsteologie op hierdie manier te verstaan, naamlik as gebore in die oortuiging dat die lewende God bemoeienis maak met die geslagte, in die talle kulturele, historiese en organiese verbande waarin konkrete mense hulleself bevind. 
Uit die voorafgaande blyk die dubbele motief reeds oormatig duidelik. Gereformeerdes is tegelyk passievol geïnteresseerd in en betrokke by die werklikheid, by húlle eie, partikuliere, historiese, hier-en-nou werklikheid, én passievol daarvan oortuig dat dié werklikheid nog nie ten volle gestalte gee aan die heilswil van die lewende God nie, en daarom verander, hernuwe, ge-reformeer, radikaal getransformeer behoort te word.

Dis dus om dié rede dat Richard Niebuhr in sy invloedryke geskrif (1951) oor die verhouding tussen Christendom en kultuur die gereformeerde tradisie kon tuisbring onder wat hy "Christ transforming culture" sou noem - êrens tussen die uiterste pole van Christus téén die kultuur en Christus ván die kultuur. Wanneer ook al gereformeerdes hulle teen die kultuur sou opstel omdat hulle onbetrokke wil wees, belangstelling daarin verloor, dink dat die geestelike belangriker is as die aardse, verloën hulle die gereformeerde passie. Wanneer ook al hulle, op omgekeerde wyse, so betrokke sou raak en so entoesiasties oor welke kulturele, politieke of sosiale strewes of prestasies ook al dat hulle dit begin sien as die suksesvolle gestaltegewing aan Gods wil self, verloën hulle eweneens dié passie. Die gereformeerde patos lê êrens tussen-in, aktief betrokke, ja, maar krities en voortdurend transformerend.

Is dit moontlik om daarby verder te gaan, en selfs die motiewe te probeer verwoord van waaruit gereformeerdes hierdie kritiese betrokkenheid beoefen? In welke rigting behoort die transformasie immers te geskied? $\mathrm{Nie}$ bloot enige vernuwing ter wille van verandering self $\mathrm{kan}$ tog die bedoeling wees nie - aangesien enige vernuwing tog juis ook in dieselfde kritiese lig bejeën behoort te word?

Hier behoort 'n mens versigtig te wees, vanweë die historiese rykdom en kompleksiteit van die tradisie. Daar sal legitieme sake uitgemaak kon word vir' $n$ verskeidenheid van tipies gereformeerde motiewe. Tog sou twee sonder enige twyfel daarby hoort, naamlik vryheid en geregtigheid.

Oor die sentraliteit van vryheid binne die gereformeerde lewensgevoel bestaan daar eenstemmigheid - hoe kompleks dit ook al mag wees. Sekerlik het die gereformeerde tradisie selfs 'n groot bydrae gelewer tot die historiese ontwikkeling van wat vandag bekend staan as die vryhede waarop moderne, demokratiese samelewings gebou is. As Hegel reg is in sy beskrywing van die Protestantisme as "godsdiens van vryheid", is die gereformeerde tradisie beslis daarby ingesluit. Tog staan die tipies gereformeerde siening van vryheid op sovele punte in spanning met moderne ideale van individuele keuse-vryhede dat 'n mens ook uiters versigtig sou moes wees met 'n presiese beskrywing van dié verhouding (vir die gereformeerde siening, vergelyk byvoorbeeld Busch 1998, Moltmann 1990, en byvoorbeeld die 
werk van Huber vir die kritiese afstand tussen die evangeliese en moderne vryheidsbegrippe, Huber 1983, 1989, 1990, 1993, 1995 en 1996).

Die gereformeerde siening van vryheid — dié vryheid wat God volgens Zwingli se beroemde woorde gunstig gesind is; of dit nou om Calvyn se aangrypende bespreking van vryheid handel; of om Barth se bekende, komplekse sieninge van vryheid (sien Green 1989, of die uitstekende Webster 1998); of om die bevrydende waarheid waarvan Willie Jonker praat (Jonker 1984) - hang té ten nouste saam met verantwoordelikheid, met roeping, met bevry-word, en ja, met diensbaarheid, om gemaklik met moderne vryheidsideale vereenselwig te kan word, hetsy individualisties en liberaal van aard, hetsy romanties-nasionalisties soos in die negentiende eeuse Duitse denke en sy neerslag in die apartheidsideologie.

Dieselfde geld vir die motief van geregtigheid. Weer eens speel dit 'n sleutelrol in die gereformeerde lewensgevoel. Trouens, as Calvyn reeds die Christelike lewe samevattend beskryf in die Institusie (vergelyk Leith 1949), doen hy dit as die honger en dors na geregtigheid — en vir dié lewe in die geregtigheid is die navolging, die bereidheid tot selfverloëning, die kruisdra, en alles wat daarmee gepaardgaan, gevolglik nodig!

Historici en politieke filosowe sou dan ook in groot detail aantoon hoe talle tipies gereformeerde motiewe en tendense sou bydra tot die ontwikkeling van hedendaagse ideale van geregtigheid en hulle neerslag sou vind in moderne demokratiese instellinge en praktyke. Vanaf die verkiesingsgeloof wat sou bydra tot die geboorte van die moderne subjek, deur die verbondsgedagte wat 'n beslissende rol sou vervul in die groei van die demokrasie; deur die talle geskrifte van die Hugenote soos "teenoor die tiranne" waarin gedagtes van legitieme burgerlike verset en die verdediging van minderheidsregte bevorder is; deur die invloed van die Puriteinse "covenant"-idee op die allerbelangrike Noord-Amerikaanse "constitution"; tot by die sogenaamde "vyf Calvinistiese beginsels" wat volgens regsgeleerdes sou dien as begronding vir die moderne demokratiese lewensvorm — vind geleerdes motiewe en historiese aanleidings binne die gereformeerde tradisie wat sou lei tot beliggaming van komplekse vorme van geregtigheid (sien byvoorbeeld J. W. de Gruchy 1995; ook S. de Gruchy 1992 oor geregtigheid as politieke ideaal en werklikheid by die gereformeerde Reinhold Niebuhr).

Ook die meer onlangse geskiedenis getuig egter in oorvloed van híerdie gereformeerde drif. As die Wêreldbond van Gereformeerde Kerke byvoorbeeld laat in die negentiende eeu gestig word, bemoei hulle hulself dadelik en daarna onophoudelik met sake van geregtigheid, meesal die reg van minderhede en onderdrukte groepe en mense. Gereformeerde mense en 
kerke onderskei hulleself telkens weer as diegene wat streef om op te tree as die stem van die stemloses en as die pleitbesorgers vir die swakkes en benadeeldes (vir dié verhaal, Schaeffer 1998).

As die ekumeniese beweging in die 60er en veral 70er jare van die twintigste eeu geleidelik meer positief oor menseregte begin dink en praat, is die WBGK weer eens op die voorpunt. Later volg die WBGK nie alleen die LWF se verklaring van 'n status confessionis oor rassisme in Suider-Afrika nie, maar volg dit ook op met inisiatiewe rondom kernbewapening en wêreldvrede asook rondom ekonomiese ongeregtigheid en ekologiese vernietiging, deur telkens te vra of dit nie die Christelike belydenis van geloof in die evangelie self weerspreek nie - dus deur ons dade van onreg en ons versuim van wat reg is (vergelyk Opocensky 1997, Debrecen 1997, Forrester 1997, Smit 1996a en 2002b).

Sowel die gereformeerde vroomheid as die gereformeerde erediens wat die sleutelplek inneem in die vorming van die gereformeerde vroomheid - het ten diepste te make met hierdie soort lewe voor Gods aangesig in die wêreld, in die konkrete werklikheid van elke dag, en in die soeke na die heiliging van die lewe en die verheerliking van Gods Naam.

In die erediens word beleef waarvan die gereformeerde geloof lééf, naamlik die troosvolle wete "dat ons nie aan onsself behoort nie". In hierdie woorde - waarmee Calvyn self die Christelike lewe tipeer, maar wat die Heidelbergse Kategismus ook as samevatting van die evangelie gebruik, wat Barth as hoofsom van die evangelie van vryheid beskou, wat die WBGK as motto gebruik in hulle aangrypende litanie rondom ekonomiese onreg en die ekologie (Debrecen 1997), wat verskillende gereformeerde NoordAmerikaanse kerke in die afgelope jare benut om hulle geloof opnuut mee te bely (Placher \& Willis 1992); en wat Burger gebruik as titel vir sy onlangse studie (Burger 2001) - leef die hart van die gereformeerde geloof.

Dit is die goeie nuus, dit is die samevatting van die volle troos, in lewe en in sterwe, met alles wat ons het en is. Tegelyk skuil die aanspraak, die oproep, die roeping egter ook reeds daarin. Dis presies omdat ons nie aan onsself behoort nie - en dus veilig is, bevry, en nie oor onsself hoef te vrees nie - dat ons bevry is tot diens en naasteliefde, sê Calvyn alreeds.

In die erediens gaan dit om die heiliging, ja, toon Nicholas Wolterstorff aan, maar dié heiliging word konkreet en sigbaar in geregtigheid — en só word Gods Naam verheerlik (sien die talle bydraes van Wolterstorff 1989, 1991, 1992a en 1992b, ook Smit 1997 en 2002e). Indien die diepste geestelike motief agter die gereformeerde hartstog dus die verheerliking van Gods Naam is - die soli Deo Gloria, of die ad majorem Dei gloriam (Wain- 
wright 1986, vir dié motief) — kan hierdie verheerliking nie losgemaak word van die daadwerklike lewe in die weerbarstigheid van die werklikheid na die bedoelinge van Gods Woord nie, dié lewende Woord waarin ons telkens opnuut weer die stem hoor van die sprekende God en sy Christus, deur sy Gees, na gereformeerde oortuiging.

\section{6. "CHRIST TRANSFORMING CULTURE"?}

Indien die voorafgaande - by al die veralgemening en oorsigtelikheid ook maar net naastenby 'n beskrywing bied van die gereformeerde karakter en lewensgevoel, roep dit egter indringende vrae op. Indien dit sou kon geld as 'n naastenby aanvaarbare tipering van wat gereformeerdes, gelowiges en gemeentes en kerke, veronderstel is om te wees, stel dit diepgrypende vrae rondom die praktyk van gereformeerde kerke vandag, rondom die identiteit en die roeping van talle gelowiges, gemeentes en kerke wat hulleself gereformeerd noem.

Dit behoort duidelik te wees dat dit nie die naam "gereformeerd" is wat kerke en gelowiges inderdaad gereformeerd maak nie.

Reeds Karl Barth het meermale intens met hierdie verskynsel geworstel. In een van sy bekende toesprake uit die 1920s gaan hy in op die verskynsel dat talle wat hulleself baie graag "gereformeerd" noem, en selfs die gereformeerdheid van harte wil bevorder, dit — ten minste wat hom betref - om onaanvaarbare motiewe doen en op grond van gevaarlike misverstande (Barth 1990d)

Sommige wil — uit antikwariese redes, sê hy — graag hê dat die kerk gereformeerd moet "bly". Vir hulle beteken dit egter eintlik dat die kerk moet bly soos wat hy was en soos hulle daaraan gewoond is en daarvan hou. Hulle noem dus eintlik bloot alles soos wat dit reeds is en gedoen word "gereformeerd", en wil dit graag onveranderd en behoue sien bly. Dit is oombliklik duidelik hoe 'n diepgrypende verloëning dit van die ware gereformeerde patos is.

Sommige wil — om ideologiese redes, sê Barth, dit wil sê om hulle eie belange te dien en te bevorder — graag hê dat die kerk meer gereformeerd moet "word". Vir hulle beteken dit egter eintlik net dat die kerk sekere ideale moet begin nastreef, sekere tendense moet navolg, sekere waarhede of leerstukke moet beklemtoon of sekere slagspreuke of motiewe moet verkondig. Hulle kies as't ware eklekties, eiesinnig, volgens hulle eie behoefte en belange, sekere leerstukke, temas, episodes of figure uit die gereformeerde geskiedenis en verhef dié tot normatiewe status, omdat dit hulle eie voorstellinge goed pas. Só wil hulle dan hê moet die kerk al meer word. 
Weer eens is dit egter 'n fundamentele verloëning van die egte gereformeerdheid wat juis nié in enige historiese episode of waarheid of leerstuk of figuur vasgevang kan word nie.

Sommige wil — uit emosionele redes, verduidelik Barth — graag hê dat die kerk en die gelowiges meer gereformeerd moet "voel". Vir hulle beteken dit inderwaarheid dat die kerk 'n sekere soort spiritualiteit sal leer beoefen, godsdienstigheid op 'n sekere wyse sal leer beleef, emosioneel sal raak oor dié sake - hetsy figure, gebeure, musiek, of liturgiese aktiwiteite waardeur hulle self geraak en geroer voel. Weer eens, egter, sien hy dit as verraad aan die ware gereformeerde tradisie, waarin die klem nooit was op die bevordering van een soort emosionaliteit of die nabootsing van of gehegtheid aan een of ander figuur — insluitende Calvyn self — as 'n voorbeeld van vroomheid nie.

Kortom, of mense verlang dat die kerk gereformeerd sal bly, sal word of sal voel, volgens Barth berus al drie dié strewes op 'n wanopvatting van wat gereformeerd ten diepste beteken, te wete die voortdurende luister na die lewende spreke van die lewende God en sy Christus deur sy Woord en Gees tot sy verbondsvolk, die gemeente, deur die gange van die tyd, en die bereidheid om in die volheid van die alledaagse lewe voortdurend vernuwe te word in ooreenstemming met dié Woord. Barth noem dit self die "Skrifbeginsel”, wat volgens hom nie 'n formele beginsel is nie, maar 'n materiële, inhoudelike belydenis: só is God en só handel God met ons (Barth 1990f, ook 1990c, 1990e).

Indien dit egter só is, berus van die vernaamste vorme van kritiek wat teen die gereformeerde geloof en tradisie uitgeoefen word egter - eweneens! - op klaarblyklike misverstande (vir 'n soortgelyke argument, sien die bekende Hesselink 1983). Hier word sake diep ironies, indien nie tragies nie. Presies dit wat talle mense ansien as tipies gereformeerd en wat hulle as totaal onaanvaarbaar en selfs verwerplik beskou, is eintlik juis wat die gereformeerde lewe nié veronderstel is om te wees nie! Die kritiek op die gereformeerde tradisie word dikwels opgeroep nie deur egte voorbeeld van gereformeerde lewe nie, maar juis deur die talle verloënings daarvan in historiese gestaltes. Die misnoeë van talle mense met wat hulle "gereformeerd" noem, is inderwaarheid 'n misnoeë met wat die gereformeerde tradisie juis nié moes wees nie - maar dikwels tragieserwys inderdaad is.

Ten minste vier sulke karikature van die gereformeerde lewe, wat meermale aanleiding gee tot skerp kritiek, ook tans in Suid-Afrikaanse kringe, is welbekend en opvallend. Gereformeerdes word naamlik dikwels vandag hier beskuldig van sektariese afsydigheid ("hulle wil met niemand saam werk nie"), van selfgenoegsame arrogansie ("hulle dink hulle weet presies 
wat waar en reg en goed is"), van onbuigsame onbekeerlikheid ("hulle kan en wil nie verander en vernuwe nie") en van onbetrokke afsydigheid ("hulle is nie geïnteresseerd in die publieke lewe en in die nood van mense nie").

$\mathrm{Al}$ vier dié klagtes, indien hulle gegrond is en inderdaad geld van gereformeerde gelowiges en gemeentes se lewe, sou slegs glashelder aantoon hoe die betrokke gelowiges en gemeentes die hartstog van die gereformeerde geloof self êrens langs die pad versaak het. Juis die vier aspekte van die gereformeerde visie waarna verwys is, weerspreek immers punt vir punt hierdie soort beskuldiginge aan gereformeerde adres.

Dis onvoorstelbaar dat gereformeerdes in sektariese afsydigheid hulleself sou kon of wou afskei van ander Christene en geloofsgemeenskappe, aangesien hulle juis van harte hulleself sien as deel van die één katolieke en ekumeniese Christenheid.

Dis ondenkbaar dat gereformeerdes deur selfgenoegsame arrogansie te kenne sou wou gee, deur woorde of dade, dat hulle hulself as meerderwaardig of as reeds in besit van die volle waarheid sou beskou, aangesien dit die diepste patos van die voortdurende en ootmoedige luister na Gods lewende Woord en die bereidheid tot voortgaande hervorming sou verloën.

Dis onmoontlik dat gereformeerdes vanweë onbuigsame onbekeerlikheid traag sou wees om te vernuwe en om vernuwe te word, en sou trag om alles soos wat dit vroeër was te beskou as "gereformeerd" en gevolglik ook soos dit in die toekoms behoort te wees en te bly, aangesien dit die drang tot voortdurend nuwe gestaltegewing aan die belydenis van die Woord fundamenteel sou weerspreek.

Dit sou onaanvaarbaar wees indien gereformeerdes hulleself uit onbetrokke apatie afsluit van die nood en die vrae van die wêreld, die samelewing, die omgewing en die oomblik waarin hulle leef, aangesien dit die hartstog vir die verheerliking van Gods heilige Naam in die volle werklikheid sou prysgee.

Die geskiedenis ken uiteraard tallose voorbeelde waar die gereformeerde passie van "Christ transforming culture" óf skeef geloop het met bittere en beskamende gevolge, óf so opgegee en versaak is dat die kerke onherkenbaar geword het as gereformeerde kerke. Bloot die woorde in die naam van 'n kerk waarborg nie getrouheid aan die tradisie nie, net soos getrouheid in een historiese oomblik geen waarborg is van blywende trou in daaropvolgende historiese fases nie. Juis vanweë die aard van die gereformeerde oortuiging bly die roeping elke oomblik nuut.

Die jubilaris was self diep bewus van dié uitdagings en versoekinge tot selfverloëning waarvoor gereformeerde gelowiges en kerke voortdurend staan. 
Reeds in sy intreerede wonder hy oor die gesag van die kerk se getuienis in die lig van die aangrypende woorde van Chesterton oor "all the easy speeches that comfort cruel men" (Potgieter 1983:2).

Trouens, die jubilaris was gedurende sy jare as geestelike leier in die kerk waarskynlik presies op dié vier sleutel-aspekte van die gereformeerde eieaard die indringendste uitgedaag, soos blyk uit die oorheersende temas van sy eie werk en lewe. Hy het te make gehad met allerlei weieringe ten aansien van die eenheid van die kerk, met vele misverstande rondom die gesag van Gods lewende Woord, met diepe huiwering om te bely en dan daadwerklik te beliggaam, en met verbreide terugdeins voor die kompleksiteit en ambiguïteit van betrokkenheid in die samelewing in diens van vryheid en geregtigheid. Terugskouend sal hy waarskynlik kan sê dat presies dié vier probleemvelde die meeste van sy tyd en energie en denke geverg het oor die afgelope dekades heen — wat begryplik sou wees, want wat op die spel was en steeds is agter al vier hierdie verskyningsvorme van een en dieselfde uitdaging is die aard van die gereformeerde lewe self in moderne samelewings, en spesifiek in Suider-Afrika.

In die lewe van elke gereformeerde kerk is daar ook ander kragvelde aan die werk, ander invloede aanwesig, ander lojaliteite wat aanspraak maak as bloot net die gereformeerde erfenis self. Só was en is dit ook in die N.G. Kerk, waarin die jubilaris geroepe was om geestelike leiding te verskaf (sien die verhelderende Jonker 1998b oor drie spesifieke kragvelde binne die N.G. Kerk, en vir die worsteling binne die N.G. Kerk self om te verander, die boeiende Jonker 1998a), en só is dit steeds in hierdie kerke-familie. Mag iets van die jubilaris se persoonlike integriteit, eerlikheid en passie vir "die gereformeerde Skrifbeginsel" hierdie kerke en hulle geestelike leierskap bly vergesel op die pad vorentoe. 


\section{BIBLIOGRAFIE}

AALDERS C

1969. Spiritualiteit. 's-Gravenhage: Boekencentrum.

\section{AdONIS J C}

1988. 'n Gereformeerde kerkorde? Opmerkings oor die kerkorde van die Verenigende Gereformeerde Kerk in Suider-Afrika. In: Boesak \& Fourie (reds.) 1988:112-124.

BAKKER J T

1956. Coram Deo. Bijdrage tot het onderzoek naar de structuur van Luthers theologie. Kampen: Kok.

\section{BARTH K}

1922. Der Römerbrief. München: Chr. Kaiser Verlag.

1935. Das Bekenntnis der Reformation und unser Bekennen. München: Chr. Kaiser Verlag.

1938. The knowledge of God and the service of God. London: Hodder and Stoughton Publishers.

1957a. Theologische Fragen und Antworten. Zürich: Evangelischer Verlag AG. Zollikon.

1957b. Gottes Wille und unsere Wünsche. In: Barth 1957a:144-157.

1957c. Offenbarung, Kirche, Theologie. In: Barth 1957a:158-184.

1957d. Das Bekenntnis der Reformation und unser Bekennen. In: Barth 1957a: 257-258.

1990a. Vorträge und kleinere Arbeiten 1922-1925. Gesamtausgabe III. Zürich: Theologischer Verlag.

1990b. Unterricht in der christlichen Religion. Zweiter Band. Gesamtausgabe II. Zürich: Theologischer Verlag.

1990c. Das Wort Gottes als Aufgabe der Theologie. In: Barth 1990a:144-175. 1990d. Reformierte Lehre, ihr Wesen und ihre Aufgabe. In: Barth 1990a:202247.

1990e. Die Kirche und die Offenbarung. In: Barth 1990a:307-348.

1990f. Das Schriftprinzip der reformierten Kirche. In: Barth 1990a:500-544. 1990g. Wünschbarkeit und Möglichkeit eines allgemeinen reformierten Glaubensbekenntnisses. In: Barth 1990a, 604-643.

1998. Die Theologie der reformierten Bekenntnisschriften 1923. Gesamtausgabe II. Zürich: Theologischer Verlag.

\section{BAVINCK H}

1888. De katholiciteit van Christendom en kerk. Kampen: G. Ph. Zalsman.

BERKHOF H

1962. De katholiciteit der kerk. Nijkerk: G.F. Callenbach.

BOESAK W A \& FOURIE P J A (reds.)

1988. Vraagtekens oor gereformeerdheid? Belhar: LUS. 


\section{BOTMAN H R}

1993. Discipleship as transformation? Towards a theology of transformation. Unpublished thesis. Bellville: UWC.

1996. 'Dutch' and Reformed and 'Black' and Reformed in South Africa: a tale or two traditions on the move to unity and responsibility. In: R.A. Wells (ed.), Keeping faith. Grand Rapids, MI: Wm B. Eerdmans:85-105.

BOUWSMA W J

1988. John Calvin: a sixteenth-century portrait. New York: Oxford University Press.

Bouwsma W J \& Wuellner W (eds.)

1987. Calvinism as theologia rhetorica: protocol of the fifty-fourth colloquy. Berkeley, Ca: Center for Hermeneutical Studies in Hellenistic and Modern Culture.

Burger C W

2001. Ons weet aan wie ons behoort. Nuut gedink oor ons gereformeerde tradisie. Wellington: Lux Verbi BM.

BusCH E

1998. Der Freiheit zugetan. Neukirchen: Neukirchen-Vluyn.

\section{BUTIN P W}

1995. Revelation, redemption, and response. Calvin's trinitarian understanding of the divine-human relationship. New York: Oxford University Press.

\section{CALVIN J}

1971. Selections from his writings. Ed. J. Dillenberger, Garden City.

1977. Institutes of the Christian religion. Ed. J. T. McNeill, tr. F. L. Battles. Philadelphia: Westminster Press.

\section{COMPIER D H}

1999. What is rhetorical theology? Harrisburg, PA: Trinity Press International. 2001. John Calvin's rhetorical doctrine of sin. Lewiston, NY: Edwin Mellen Press.

De GRUCHY J W

1991. Liberating reformed theology. Grand Rapids: Wm. B. Eerdmans Jr. 1995. Christianity and democracy. Cape Town: David Philip.

DE GRUCHY S

1992. Not liberation but justice. Unpublished doctoral thesis, Bellville: UWC.

DURAND J J F

1986. Kontemporêre modelle vir die verhouding van kerk en samelewing. In: Teks binne konteks. Bellville: UWK:13-37.

\section{FORRESTER D B}

1997. Christian justice and public policy. Cambridge University Press: Cambridge.

\section{GANOCZY A \& SCHELD S}

1983. Die Hermeneutik Calvins: geistesgeschichtliche Voraussetzungen und Grundzüge. Wiesbaden: Steiner. 


\section{GERRISH B}

1999. Tradition in the modern world: the Reformed habit of mind. In: Willis \& Welker (eds.) 1999:3-20.

GREEN C (ed.)

1989. Karl Barth. Theologian of freedom. Glasgow: Collins.

\section{HESSELINK I J}

1983. On being reformed. Distinctive characteristics and common misunderstandings. Ann Arbor, MI: Servant Books.

\section{HORN J N}

1987. Teologie of politiek? Ongepubliseerde proefskrif. Bellville: UWK.

\section{HUBER W}

1983. Folgen christlicher Freibeit. Ethik und Theorie der Kirche im Horizont der Barmer Theologischen Erklärung. Neukirchen: Neukirchen Verlag.

1989. Solidarität und Freiheit: Maßstäbe für eine humane Zukunftsgestaltung. In: Wofür wir streiten — Solidarität und Freibeit. Köln: Bund Verlag:15-34.

1990. Der Protestantismus und die Ambivalenz der Moderne. In: Moltmann (Hrsg.) 1990:29-65.

1993. Die Verbindlichkeit der Freiheit. Über das Verhältnis zwischen Verbindlichkeit und Freiheit in der evangelischen Ethik. Zeitschrift für Eangelische Etbik 37:70-82.

1995. Gestalten und Wirkungen christlicher Freiheit in Kirche und Gesellschaft heute. Zeitschrift für Theologie und Kirche 92/2:278-286.

1996. Christliche Freiheit in der freiheitlichen Gesellschaft. Evangelische Theologie 56:99-116.

\section{JACOBS P}

1959. Theologie Reformierter Bekenntnisschriften in Grundzügen. Neukirchen: Neukirchener Verlag.

\section{JONES S}

1995. Calvin and the rhetoric of piety. Louisville: Westminster/John Knox.

\section{JONKER W D}

1965. Om die regering van Christus in sy kerk. Pretoria: Unisa.

1981. Die Gees van Christus. Pretoria: NGKB.

1982. Kritiese verwantskap? Opmerkings oor die verhouding van die pneumatologie van Calvyn tot dié van die Anabaptiste. In: E. Brown (red.) Calvyn aktueel? Kaapstad: NGKU:72-89.

1992. Catholicity, unity and truth. In: P. Schrotenboer (ed.) Catholicity and secession: a dilemma? Kampen: Kok:16-27.

1994. Bevrydende waarheid. Wellington: Hugenote-Uitgewers.

1998a. Selfs die kerk kan verander. Kaapstad: Tafelberg-Uitgewers.

1998b. Kragvelde binne die Kerk. Aambeeld 26/1:11-14. 


\section{LEHMANN P}

1963. Ethics in a Christian context. New York: Harper \& Row.

\section{LEITH J H}

1949. A study of John Calvin's doctrine of the Christian life. New Haven: Yale dissertation (1982. Ann Arbor, Michigan: University Microfilms Inc.).

1981. Introduction to the Reformed tradition. A way of being the Christian community. Atlanta, Ga: John Knox.

\section{LOMBARD C}

1996. Adama, thora en dogma: die samehang van aardse lewe, Skrif en dogma in die teologie van A.A. van Ruler. Ongepubliseerde proefskrif. Bellville: UWK.

LOsSKY $\mathrm{N}$ et al. (eds.)

1991. Dictionary of the ecumenical movement. Geneva: WCC.

MCKIM D (ed.)

1992. Major themes in the Reformed tradition. Grand Rapids, MI: Wm. B. Eerdmans.

\section{Meeks M D}

1989. God the economist. Fortress Press: Minneapolis.

1995. God's oikonomia and the new world economy. In: Stackhouse et al. (eds.) 1995:111-126.

MoltmanN J (Hrsg.)

1990. Religion der Freibeit. Protestantismus in der Moderne. München: Chr. Kaiser.

NiEBUHR H R

1951. Christ and culture. New York: Harper \& Row.

NIESEL W U.A. (Hrsg.)

1938. Bekenntnisschriften und Kirchenordnungen der nach Gottes Wort reformierten Kirche. Zürich: Evangelischer Verlag.

NiJENHUIS W

1959. Calvinus oecumenicus. Calvijn en de eenheid der kerk in het licht van zijn briefwisseling. 's-Gravenhage: Martinus Nijhoff.

\section{OPITZ P}

1994. Calvins theologische Hermeneutik. Neukirchen-Vluyn: Neukirchener Verlag.

\section{OPOCENSKY M}

1997. Christ's call to faithfulness, justice and unity. Reformed World 47/2:50-59.

PELIKAN J

1984. Reformation of church and dogma (1300-1700). The Christian Tradition, Vol. 4. Chicago: University of Chicago Press. 


\section{Placher W C \& WILLIS-WATKINS D}

1992. Belonging to God. A commentary on a brief statement of faith. Louisville, Ky: Westminster/John Knox.

\section{POTGIETER P C}

1983. Die gesag van die kerk se Woord. Bloemfontein: UOVS.

1985. Hier is die Woord. Wellington: Bybelkor.

1990. Skrif, dogma en verkondiging. Kaapstad: Lux Verbi.

\section{PREECE G R}

1998. The viability of the vocation tradition in trinitarian, credal and Reformed perspective. Lewiston: The Edwin Mellen Press.

\section{Retief G J}

1984. Die verhouding tussen mortificatio en vivificatio in die leer van die heiliging by Calvyn. Ongepubliseerde proefskrif. Stellenbosch: Universiteit van Stellenbosch.

\section{SCHAEFFER J}

1998. WARC's historic commitment to justice and human rights. Reformed World 48/2:63-78.

\section{SCHWÖBEL C}

1990. Calvin. In: R. J. Coggin \& J. L. Houlden (eds.) A Dictionary of Biblical Interpretation. Philadelphia, PA: Trinity Press International:98-101.

\section{SMIT D J}

1988. Wat is gereformeerde spiritualiteit? NGTT 2:182-193.

1989. Kan spiritualiteit beskryf word? NGTT 1989/1:83-94.

1990. Theology and the transformation of culture - Niebuhr revisited. JTSA 72:9-23.

1992. Reformed theology in South Africa: a story of many stories. Acta Theologica 21/1:88-110.

1996a. Reformed ethics and economic justice. NGTT 37/3:438-455.

1996b. Theology as rhetoric? Or: guess who's coming to dinner. In: S. E. Porter \& T. H. Olbricht (eds.) Rhetoric, scripture and theology: essays from the 1994 Pretoria Conference. Sheffield: Sheffield Academic Press:400-429.

1997. Liturgy and life? On the importance of worship for Christian ethics. In: D. E. de Villiers (ed.) Christian ethics in South Africa, Scriptura 62:259-280. 1998a.Vraagtekens oor die gereformeerde integriteit? In: Vraagtekens oor die gereformeerde integriteit. Reds. Boesak \& Fourie 1988:5-19.

1998b Wat beteken "gereformeerd"? In: Boesak \& Fourie 1988:20-37.

1998c. Das Bekenntnis von Belhar: Entstehung, Inhalt, Rezeption, Relevanz. In: Das Bekenntnis von Belhar und seine Bedeutung für die reformierten Kirchen in Deutschland. Detmold: Lippische Landeskirche:17-33.

1999. Gedagtes oor die N. G. Kerk en uitdagings vir die jare vorentoe. Handelinge van die Sinode, N.G. Kerk (Wes-Kaap). 
2000. Social transformation and confessing the faith? Karl Barth's views on confession revisited. Scriptura 72(1):76-86.

2002a. Can we still be Reformed? Questions from a South African perspective. In: W. Alston \& M. Welker (eds.) Reformed theology in ecumenical perspective. Grand Rapids: Wm. B. Eerdmans (in press).

2002b. A time for confession? On the WARC project "Reformed faith and economic justice". Submitted to NGTT.

2002c. Has there been any change? On the role of the Dutch Reformed Church 1974-1990. Scriptura 76/1:119-128.

2002d. Rhetoric and ethic? A Reformed perspective on the politics of reading the Bible. In: W. Alston \& M. Welker (eds.) Reformed theology in ecumenical perspective. Grand Rapids: Wm. B. Eerdmans (in press).

2002e. "Seeing things differently" — On prayer and politics. In: L. Holness \& R. K. Wüstenberg (eds.) Theology in dialogue: the impact of the arts, humanities, and science on contemporary religious thought. Grand Rapids, MI: Wm B. Eerdmans. 2002f. Bely en beliggaam. In: P. Coertzen (red.) 350 jaar gereformeerd in SuiderAfrika. Bloemfontein: CLF:357-371.

STACKHOUSE M L et al.

1995. Christian social ethics in a global era. Abingdon Press: Nashville.

\section{STAUFFER R}

1986. The quest for church unity; from John Calvin to Isaac d'Huisseau. Allison Park, PA: Pickwick.

\section{TORRANCE T F}

1988. The hermeneutics of John Calvin. Edinburgh: Scottish Academic Press.

\section{TROELTSCH E}

1912. Protestantism and progress. A historical study of the relation of Protestantism to the modern world. London: Williams \& Norgate.

1992. The social teaching of the Christian churches. Tr. O Wyon. Louisville: Westminster/John Knox.

\section{WAINWRIGHT G}

1986. Ad majorem Dei gloriam. In: D.K. McKim (ed.), How Karl Barth changed my mind. Grand Rapids, MI: Wm B. Eerdmans:178-181.

1987. For our salvation. Grand Rapids, MI: Wm. B. Eerdmans.

\section{WARC}

1997. Break the chains of injustice. The 23rd General Council of the World Alliance of Reformed Churches in Debrecen, Hungary. Geneva: WARC.

\section{WEBER M}

1975. Die Protestantische Ethik. Eine Aufsatzsammlung. Hamburg: Siebenstern Taschenbuch Verlag. 


\section{WEBSTER J B}

1998. Barth's moral theology. Human action in Barth's thought. Grand Rapids, Mi: Wm. B. Eerdmans.

WEERDA J R

1964. Ordnung zur Lehre. Zur Theologie der Kirchenordnung bei Calvin. Nach Gottes Wort reformierte Kirche (Theologische Bücherei. Neudrucke und Berichte aus dem 20. Jahrhundert. Band 23. Historische Theologie). München: Chr. Kaiser Verlag:132-161.

WILLIS D \& WeLKER M (eds.)

1999. Toward the future of reformed theology. Tasks, topics, traditions. Grand Rapids, MI: Wm. B. Eerdmans.

WOLTERSTORFF $\mathrm{N}$

1983. Until justice and peace embrace. Grand Rapids: Wm. B. Eerdmans.

1989. Liturgy, justice, and holiness. The Reformed Journal, December:12-20.

1991. Justice as a condition of authentic liturgy. Theology Today XLVIII/1:6-21.

1992a. The Reformed liturgy. In: McKim (ed.):273-304.

1992b. Worship and justice. In: McKim (ed.):311-318.

Trefwoorde

Gereformeerde geloof

Transformasie

Kultuur
Keywords

Reformed faith

Transformation

Culture 